\title{
A VARIAÇÃO DE ESCALA NAS METODOLOGIAS DE FRAGILIDADE E VULNERABILIDADE NA BACIA HIDROGRÁFICA DO RIO JUNDIAÍ/SP
}

\author{
THE CHANGE OF SCALE IN METHODOLOGIES OF FRAGILITY AND \\ VULNERABILITY IN THE JUNDIAÍ RIVER BASIN/SP
}

\author{
LO CAMBIO DE ESCALA EN LAS METODOLOGÍAS DE FRAGILIDAD \\ Y VULNERABILIDAD EN LA CUENCA DEL RÍO JUNDIAÍ/SP \\ Mariana Guarnier Fagundes - Universidade de São Paulo - São Paulo - São Paulo - Brasil \\ mari_fagundes2000@yahoo.com.br
Alfredo Pereira de Queiroz Filho - Universidade de São Paulo - São Paulo - São Paulo - Brasil aqueiroz@usp.br

\begin{abstract}
Resumo
Este trabalho analisa a variação de escala nas metodologias de fragilidade ambiental e de vulnerabilidade natural à perda de solo na bacia hidrográfica do Rio Jundiaí, em São Paulo. Foram geradas quatro cartas, duas de fragilidade e duas de vulnerabilidade, nas escalas 1:50.000 e 1:250.000. As cinco classes de cada metodologia foram equiparadas e suas respectivas áreas e percentuais de sobreposição foram confrontados. Constatou-se a tendência da metodologia de Crepani a atenuar os valores extremos e acentuar os valores intermediários, e a de Ross a atenuar os valores intermediários e acentuar os extremos. Observou-se que, em ambas as metodologias, o nível do detalhamento de classificação das áreas foi diretamente proporcional à escala das bases cartográficas disponíveis. Assim, quanto maior a escala dos mapas temáticos, maior deverá ser a diferença entre os mapas de fragilidade ambiental e vulnerabilidade. E, quanto menor for a escala, maior deverá ser a sua semelhança.
\end{abstract}

Palavras-chave: escala, fragilidade, vulnerabilidade.

\begin{abstract}
This paper analyzes the change of scale in the methodologies of environmental fragility and natural vulnerability to soil loss in the Jundiaí river basin, SP. Four maps were generated, two of fragility and two of vulnerability, scales 1:50,000 and 1:250,000. The five classes of each methodology were equated, and their respective areas and percentages of overlap were confronted. It was noted the tendency of Crepani's methodology to reduce the extreme values and accentuate the intermediate values, and of Ross to reduce the intermediate values and accentuate the extremes. It was observed that in both methods, the level of detail of classification's areas was directly proportional to the scale of available cartographic bases. Thus, the greater the scale of thematic maps, the greater will be the difference between the maps of fragility and vulnerability. And, the smaller the scale of the maps, the greater should be your likeness.
\end{abstract}

Key words: scale, fragility, vulnerability.

\section{Resumen}

Este trabajo analiza lo cambio de escala en las metodologías de la fragilidad del medio ambiente y de la natural vulnerabilidad a la pérdida de suelo en la cuenca del río Jundiaí, SP. Se prepararon cuatro mapas, dos de fragilidad y dos de vulnerabilidad, escalas 1:50.000 y 1:250.000. Las cinco clases de cada metodología fueron equiparadas, y sus respectivas áreas y porcentajes de superposición fueron confrontados. Se observó la tendencia de la metodología de Crepani para reducir los valores extremos y acentuar los valores intermedios, y de Ross para reducir los valores intermedios y acentuar los extremos. En ambos métodos, el nivel de detalle de las áreas de clasificación era directamente proporcional a la escala de las bases cartográficas disponibles. Así, 
cuanto mayor sea la escala de los mapas temáticos, mayor deberá ser la diferencia entre los mapas de fragilidad y la vulnerabilidad. Y, cuanto menor sea la escala de los mapas, mayor debe ser su semejanza.

Palabras clave: escala, fragilidad, vulnerabilidad.

\section{Introdução}

Os estudos ambientais estão indissociavelmente relacionados à sua abrangência espacial. De acordo com Goodchild e Quattrochi (1997), a escala pode ser considerada como um dos aspectos fundamentais de uma pesquisa, pois, em princípio, quanto mais próximo o observador se colocar do seu objeto de estudo, mais detalhes ele perceberá. Nas análises geográficas, segundo Fabrikant (2001), a escala está relacionada ao tamanho dos objetos estudados e ao nível de detalhe que será utilizado. A natureza dos fenômenos determina a escala, que define o seu grau de generalização.

Determinar a escala dos processos que incidem sobre a paisagem é uma questão central da ecologia (Turner, 1989). Por outro lado, as incertezas decorrentes das alterações da escala causam justificada preocupação a áreas como o Sensoriamento Remoto e a Análise Espacial (Openshaw, 1977; Marceau; Hay, 1999; Lechner et al., 2012).

Nos Sistemas de Informações Geográficas (SIG), que proporcionam grande facilidade de alteração da escala de visualização dos mapas, o nível de detalhamento das representações cartográficas é fundamental ao processamento de dados (Queiroz Filho; Rodrigues, 2007). A escala é um atributo essencial aos sistemas que manipulam dados sobre recursos naturais e gerenciamento ambiental (Aspinall; Pearson, 2000; Mckinney; Cai, 2002; Geneletti, 2004; Valavanis et al., 2004; Ying et al., 2007).

Pesquisas recentes, que compararam as metodologias de fragilidade e a vulnerabilidade, enfatizaram, ao menos, três aspectos distintos: validação, adaptação e extrapolação dos modelos. Santos e Sobreira (2008) pontuam que a proposta de Ross (1994) se ajustou melhor à área de estudo avaliada. Consideraram que ambas as metodologias foram valiosas na diferenciação básica entre os ambientes pesquisados, mas que não substituem as análises de campo para a avaliação dos problemas e características ambientais. Melo e Santos (2010) adaptaram a proposta de Ross (1994), substituindo a importância da variável dissecação do relevo pela da cobertura vegetal, e constataram a maior compatibilidade dessa metodologia com a área de estudo. No contexto das redes neurais artificiais, Sporl, Castro e Luchiari (2011) observaram que os resultados dos modelos propostos, 
quando comparados entre si, apresentam baixa correlação. Destacaram a arbitrariedade e a subjetividade do processo de elaboração dos modelos ambientais e também ponderaram que os especialistas concordam nos conceitos e no padrão de avaliação das variáveis que compõem os sistemas ambientais, mas que discordam na forma de construir os modelos.

Nesse contexto, o artigo visa a comparar o efeito da variação de escala nas metodologias desenvolvidas por Ross (1994) e por Crepani et al. (2001), na geração de cartas de fragilidade ambiental e de vulnerabilidade natural à perda do solo na bacia hidrográfica do Rio Jundiaí, no estado de São Paulo. Para compará-las, foram geradas quatro cartas em um SIG, duas de fragilidade e duas de vulnerabilidade, nas escalas 1:50.000 e 1:250.000. As cinco classes de cada metodologia foram equiparadas, e suas respectivas áreas e percentuais de sobreposição foram confrontados.

\section{Área de estudo}

A área de estudo está localizada na bacia hidrográfica do Rio Jundiaí (SP) e envolve os municípios de Atibaia, Cabreúva, Cajamar, Campo Limpo Paulista, Francisco Morato, Franco da Rocha, Indaiatuba, Itatiba, Itupeva, Itú, Jarinú, Jundiaí, Louveira, Mairiporã, Salto e Várzea Paulista (Figura 1).

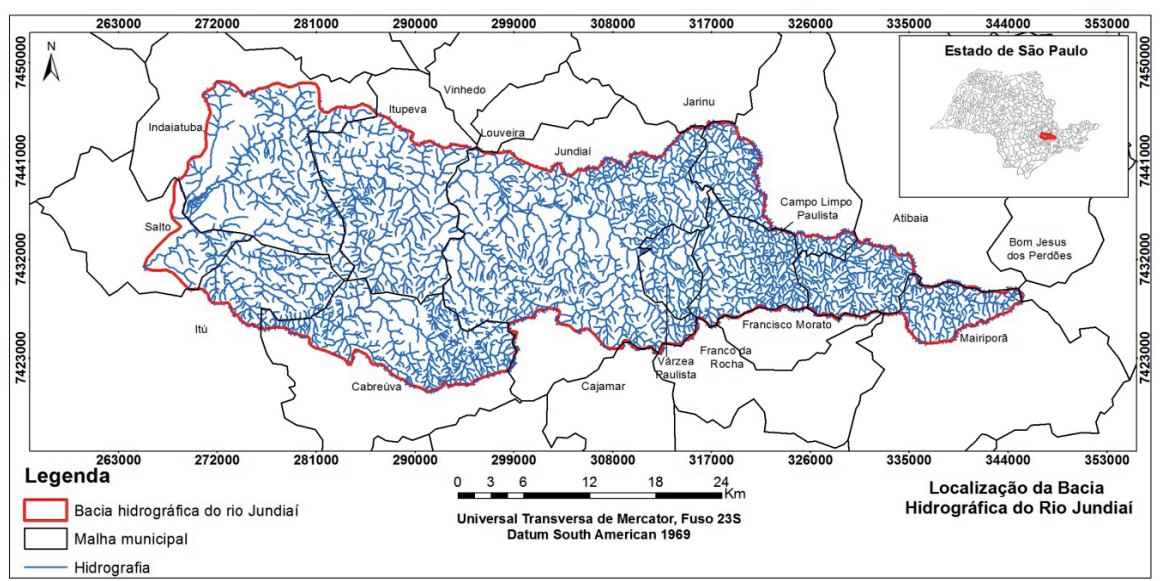

Figura 1 - Localização bacia hidrográfica do Rio Jundiaí, SP Fonte: IBGE (1985) 
A bacia hidrográfica foi delimitada a partir das curvas de nível, da hidrografia e dos pontos cotados. Os critérios para sua escolha foram o grau de dissecação do relevo, disponibilidade de dados, acessibilidade e distância do laboratório de pesquisa.

\section{Metodologias}

a) Fragilidade ambiental

A metodologia de fragilidade ambiental, desenvolvida por Ross (1994), baseia-se na análise integrada dos temas geomorfologia (índice de dissecação do relevo), solos, cobertura vegetal/uso da terra e clima (regime pluviométrico). De acordo com o autor, o estudo da fragilidade ambiental em áreas antropizadas varia de acordo com as características genéticas do meio físico e com a intensidade da intervenção humana, e também permite a classificação e a análise dos graus de fragilidade da área analisada e suas potencialidades de uso.

A metodologia propõe que cada tema seja hierarquizado em cinco classes, de acordo com as respectivas fragilidades ocasionadas pelo escoamento superficial difuso e concentrado das águas pluviais. As variáveis mais estáveis são associadas a valores próximos de 1; as intermediárias, ao redor de 3; e as instáveis, em aproximadamente 5.

A classificação da fragilidade é realizada pela combinação das quatro variáveis: geomorfologia (índice de dissecação do relevo), solo, cobertura vegetal/uso da terra e clima. A dissecação do relevo ( $1^{\circ}$ dígito) determina o índice de fragilidade de cada área, sendo que as demais variáveis definem o grau de hierarquização das mesmas.

A matriz de Índices de Dissecação do Relevo (Ross, 1992) foi desenvolvida a partir do Projeto RADAM Brasil, e se fundamenta na relação de densidade de drenagem/dimensão interfluvial média, para a dissecação no plano horizontal, e nos graus de entalhamento dos canais de drenagem, para a dissecação no plano vertical.

Como os mapeamentos geomorfológicos da área de estudo, do IPT (São Paulo, 1981) e de Ross (1997), estão na escala 1:500.000, utilizou-se a metodologia desenvolvida por Ross (1997) para representar as feições geomorfológicas em escalas mais detalhadas (1:50.000 e 1:250.000). Essa ampliação baseou-se na rugosidade do terreno e na densidade da drenagem da área de estudo. 
b) Vulnerabilidade à erosão

A metodologia para a elaboração de um mapa de vulnerabilidade do solo à erosão foi desenvolvida por Crepani et al. (2001), no Instituto Nacional de Pesquisas Espaciais (INPE). Seu objetivo inicial era fornecer suporte à elaboração de um Zoneamento Ecológico e Econômico para a Amazônia, promovido pelo Ministério de Meio Ambiente. Posteriormente, a metodologia foi utilizada com distintos objetivos e escalas. Seu objetivo é identificar e delimitar conjuntos estruturais e paisagísticos homogêneos, denominados Unidades Territoriais Básicas (UTBs), formados pelas "Unidades da Paisagem Natural" e pelos "Polígonos de Intervenção Antrópica" (Crepani et al., 2001).

A delimitação dessas unidades é feita a partir do processamento e da interpretação de cores e texturas de imagens de satélite (resolução de 30 metros), que posteriormente recebem o conteúdo oriundo dos temas Geologia, Geomorfologia, Pedologia, Vegetação e Climatologia.

O estágio de evolução morfodinâmica das Unidades Territoriais Básicas (UTB) é analisado de forma a construir uma escala de vulnerabilidade. Essa escala representa 21 classes de vulnerabilidade à perda de solo, distribuídas entre as situações em que há o predomínio dos processos de pedogênese (às quais se atribuem valores ao redor de 1,0) e situações de predomínio dos processos de morfogênese (às quais se atribuem valores próximos de 3,0).

Esse modelo é aplicado individualmente aos temas (Geologia, Geomorfologia, Pedologia, Vegetação e Clima) que compõem cada UTB, cujo valor é resultante da média aritmética dos valores individuais, obtidos na equação abaixo.

$$
\mathrm{V}=\underline{(\mathrm{G}+\mathrm{R}+\mathrm{S}+\mathrm{Vg}+\mathrm{C})}
$$

5

onde:

$\mathrm{V}=$ vulnerabilidade

$\mathrm{G}=$ vulnerabilidade para o tema Geologia

$\mathrm{R}=$ vulnerabilidade para o tema Geomorfologia

$\mathrm{S}=$ vulnerabilidade para o tema Solos

$\mathrm{Vg}=$ vulnerabilidade para o tema Vegetação

$\mathrm{C}=$ vulnerabilidade para o tema Clima 
c) Comparação das metodologias

A comparação, conforme Ragin (1987), fornece uma base para fazer declarações sobre as regularidades empíricas. De acordo com Avison e Fitzgerald (1995), a comparação metodológica é feita com finalidades acadêmicas e aplicadas. A acadêmica proporciona a melhor compreensão da natureza das metodologias e o aprimoramento dos processos de desenvolvimento no âmbito dos sistemas de informação. A aplicada contribui para a seleção de uma ou mais metodologias para atividades específicas.

Ainda que as metodologias de fragilidade e vulnerabilidade produzam resultados distintos, pois seus procedimentos são diferentes (Sporl; Castro; Luchiari, 2011), considera-se que elas possuem similaridades relevantes, principalmente no que se refere à finalidade, gênese e variáveis utilizadas.

No Brasil, as metodologias de Ross e Crepani são muito utilizadas em zoneamentos, diagnósticos e Estudos/Relatórios de Impacto Ambiental (EIA/RIMA). Ambas as propostas foram desenvolvidas com base nas concepções de Ecodinâmica, definidas por Tricart (1977). Visam a realizar análises integradas de dados, a partir de combinações dinâmicas de elementos físicos, biológicos e antrópicos, que tornam a paisagem um conjunto único e indissociável, em constante evolução (Sotchava, 1978). O Quadro 1 ilustra as correlações entre autores, metodologias e conceitos.

Quadro 1 - Relação conceitual das metodologias de análise

\begin{tabular}{|c|c|c|c|}
\hline \multirow{2}{*}{ AUTOR } & $\begin{array}{c}\text { PROPOSTA } \\
\text { METODOLÓGICA }\end{array}$ & \multicolumn{2}{|c|}{ CONCEITOS } \\
\hline TRICART, 1977 & Ecodinâmica & Unidades Estáveis & Unidades Instáveis \\
\hline \multirow{2}{*}{ ROSS, 1994 } & Fragilidade Ambiental & $\begin{array}{c}\text { Unidade } \\
\text { Ecodinâmica de } \\
\text { Instabilidade } \\
\text { Potencial }\end{array}$ & $\begin{array}{c}\text { Enidade } \\
\text { Ecodinâmica de } \\
\text { Instabilidade } \\
\text { Emergente }\end{array}$ \\
\hline CREPANI, 2001 & Vulnerabilidade do solo & UTB Estável & UTB Vulnerável \\
\hline
\end{tabular}

Fonte: Fagundes (2013).

As Unidades Estáveis (Unidade Ecodinâmica de Instabilidade Potencial e UTB Estável) são áreas que estão em equilíbrio dinâmico em seu estado natural. As Unidades Instáveis (Unidade Ecodinâmica de Instabilidade Emergente e UTB Vulnerável) são os ambientes naturais que foram 
modificados pelo homem, também chamados de ambientes antropizados, caracterizados pela ocorrência, entre outros, de desmatamentos, agriculturas, indústrias e urbanização.

Essas unidades são detalhadas em cada uma das metodologias. Mediante ponderações, são classificadas conforme seu grau de estabilidade/ instabilidade, variando de muito forte até muito fraca.

As metodologias de fragilidade e vulnerabilidade utilizam praticamente as mesmas variáveis, exceto a Geologia. Presente em Crepani et al. (2001), esse tema é contemplado indiretamente por Ross (1994) no conjunto da paisagem, isto é, na combinação entre solo e relevo.

Os dois modelos diferem nas análises e formas de cálculo (Quadro 2). Enquanto Crepani et al. (2001) trabalham com valores médios, Ross (1994) usa o agrupamento dos índices das variáveis e utiliza o relevo como geoindicador (Sporl, 2001).

Quadro 2 - Síntese da comparação

\begin{tabular}{|c|c|c|c|c|}
\hline Parâmetros & \multicolumn{2}{|c|}{ Ross } & \multicolumn{2}{|c|}{ Crepani } \\
\hline Análise & \multicolumn{2}{|c|}{$\begin{array}{l}\text { A variável da dissecação do relevo é mais } \\
\text { expressiva para a determinação do grau } \\
\text { de fragilidade, e as demais variáveis a } \\
\text { hierarquizam. }\end{array}$} & \multicolumn{2}{|c|}{$\begin{array}{l}\text { A utilização da média aritmética entre } \\
\text { as variáveis pressupõe que todas elas } \\
\text { possuem a mesma importância (peso) para } \\
\text { estabelecer o grau e fragilidade das UTBs. }\end{array}$} \\
\hline Cálculo & \multicolumn{2}{|c|}{$\begin{array}{l}\text { Apresenta como resultado uma fragilidade } \\
\text { baseada na dissecação do relevo, mas que } \\
\text { pode não refletir as características da área, } \\
\text { pois nem sempre o relevo mais dissecado } \\
\text { é o mais frágil, já que a fragilidade também } \\
\text { depende de outras variáveis (tipo de rocha, } \\
\text { clima etc.). }\end{array}$} & \multicolumn{2}{|c|}{$\begin{array}{l}\text { Apresenta como resultado uma fragilidade } \\
\text { decorrente da média aritmética da } \\
\text { ponderação dos temas, fazendo com que } \\
\text { as fragilidades extremas (muita fraca e } \\
\text { muito forte) sejam atenuadas, ou seja, uma } \\
\text { área com alta vulnerabilidade para um } \\
\text { dos temas poderá ser atenuada pela baixa } \\
\text { vulnerabilidade de outro tema. }\end{array}$} \\
\hline \multirow[t]{2}{*}{$\begin{array}{l}\text { Escala de } \\
\text { análise }\end{array}$} & \multicolumn{2}{|c|}{$\begin{array}{l}\text { A metodologia trabalha sobre a } \\
\text { compartimentação da área de estudo } \\
\text { baseada na matriz de dissecação do relevo, } \\
\text { o que a torna mais aplicável em escalas } \\
\text { regionais. }\end{array}$} & \multicolumn{2}{|c|}{$\begin{array}{l}\text { A metodologia trabalha sobre a } \\
\text { compartimentação da área de estudo } \\
\text { baseada na imagem de satélite, o que } \\
\text { permite o trabalho em várias escalas. }\end{array}$} \\
\hline & $\begin{array}{l}50.000 \text { - Maior } \\
\text { etalhamento dos } \\
\text { rodutos }\end{array}$ & $\begin{array}{l}\text { 1:250.000 - Menor } \\
\text { detalhamento dos } \\
\text { produtos }\end{array}$ & $\begin{array}{l}\text { 1:50.000 - Maior } \\
\text { detalhamento dos } \\
\text { produtos }\end{array}$ & $\begin{array}{l}\text { 1:250.000 - Menor } \\
\text { detalhamento dos } \\
\text { produtos }\end{array}$ \\
\hline Relevo & $\begin{array}{l}\text { Maior densidade de } \\
\text { drenagem, menores } \\
\text { interflúvios, } \\
\text { declividade e formas } \\
\text { de relevo mais } \\
\text { marcantes. }\end{array}$ & $\begin{array}{l}\text { Menor densidade } \\
\text { de drenagem, } \\
\text { maiores interflúvios, } \\
\text { declividade e formas } \\
\text { de relevo mais } \\
\text { suavizadas. }\end{array}$ & $\begin{array}{l}\text { Maior densidade de } \\
\text { drenagem, menores } \\
\text { interflúvios, } \\
\text { declividade e formas } \\
\text { de relevo mais } \\
\text { marcantes. }\end{array}$ & $\begin{array}{l}\text { Menor densidade } \\
\text { de drenagem, } \\
\text { maiores interflúvios, } \\
\text { declividade e formas } \\
\text { de relevo mais } \\
\text { suavizadas. }\end{array}$ \\
\hline
\end{tabular}




\begin{tabular}{|c|c|c|c|c|}
\hline \multirow{2}{*}{$\begin{array}{c}\text { Parâmetros } \\
\\
\text { Solo }\end{array}$} & \multicolumn{2}{|c|}{ Ross } & \multicolumn{2}{|c|}{ Crepani } \\
\hline & $\begin{array}{l}\text { Menor incidência } \\
\text { de solos profundos, } \\
\text { em função do } \\
\text { detalhamento das } \\
\text { curvas de nível e } \\
\text { drenagem. }\end{array}$ & $\begin{array}{l}\text { Maior incidência } \\
\text { de solos profundos, } \\
\text { em função da } \\
\text { generalização das } \\
\text { curvas de nível e } \\
\text { drenagem. }\end{array}$ & $\begin{array}{l}\text { Menor incidência } \\
\text { de solos profundos, } \\
\text { em função do } \\
\text { detalhamento das } \\
\text { curvas de nível e } \\
\text { drenagem. }\end{array}$ & $\begin{array}{l}\text { Maior incidência } \\
\text { de solos profundos, } \\
\text { em função da } \\
\text { generalização das } \\
\text { curvas de nível e } \\
\text { drenagem. }\end{array}$ \\
\hline Uso do solo & $\begin{array}{l}\text { Maior diversidade } \\
\text { de classes de uso do } \\
\text { solo, e limites mais } \\
\text { precisos. }\end{array}$ & $\begin{array}{l}\text { Menor diversidade } \\
\text { de classes de uso } \\
\text { do solo, e limites } \\
\text { menos precisos. }\end{array}$ & $\begin{array}{l}\text { Maior diversidade } \\
\text { de classes de uso do } \\
\text { solo, e limites mais } \\
\text { precisos. }\end{array}$ & $\begin{array}{l}\text { Menor diversidade } \\
\text { de classes de uso } \\
\text { do solo, e limites } \\
\text { menos precisos. }\end{array}$ \\
\hline Clima & \multicolumn{4}{|c|}{$\begin{array}{l}\text { Utilizou-se a mesma base em ambas as escalas devido à falta de critérios para } \\
\text { generalização e/ou detalhamento dos ajustes na correlação espacial dos métodos de } \\
\text { interpolação. }\end{array}$} \\
\hline Geologia & $\begin{array}{l}\text { Utilizou-se a mesma } \\
\text { base em ambas as } \\
\text { escalas devido à } \\
\text { carência de bases } \\
\text { para o detalhamento } \\
\text { das unidades } \\
\text { geológicas. }\end{array}$ & Não utilizada. & $\begin{array}{l}\text { Utilizou-se a mesma } \\
\text { base em ambas as } \\
\text { escalas devido à } \\
\text { carência de bases } \\
\text { para o detalhamento } \\
\text { dos das unidades } \\
\text { geológicas. }\end{array}$ & $\begin{array}{l}\text { Mapeamento de } \\
\text { base utilizado na } \\
\text { própria escala. }\end{array}$ \\
\hline Produto & $\begin{array}{l}\text { O maior } \\
\text { detalhamento das } \\
\text { formas de relevo } \\
\text { implica em uma } \\
\text { fragilidade ambiental } \\
\text { mais forte, devido } \\
\text { ao agrupamento dos } \\
\text { graus de fragilidade } \\
\text { ter o relevo como } \\
\text { variável principal. } \\
\text { Deste modo, as } \\
\text { classes irão conduzir } \\
\text { a uma fragilidade } \\
\text { ambiental mais forte. }\end{array}$ & $\begin{array}{l}\text { Uma vez } \\
\text { suavizada as } \\
\text { formas de relevo, } \\
\text { a fragilidade } \\
\text { ambiental será } \\
\text { atenuada, devido } \\
\text { ao agrupamento } \\
\text { dos graus de } \\
\text { fragilidade } \\
\text { ter o relevo } \\
\text { como variável } \\
\text { principal. Deste } \\
\text { modo, as classes } \\
\text { irão conduzir a } \\
\text { uma fragilidade } \\
\text { ambiental mais } \\
\text { fraca. }\end{array}$ & $\begin{array}{l}\text { O maior grau de } \\
\text { detalhamento das } \\
\text { curvas de nível } \\
\text { e densidade de } \\
\text { drenagem aumenta } \\
\text { os valores da } \\
\text { ponderação quanto } \\
\text { à estabilidade das } \\
\text { variáveis a elas } \\
\text { associadas. Essa } \\
\text { diferença reflete } \\
\text { no valor da média } \\
\text { calculada para a } \\
\text { determinação do grau } \\
\text { de vulnerabilidade } \\
\text { à perda do solo, de } \\
\text { modo a torná-las mais } \\
\text { altas. }\end{array}$ & $\begin{array}{l}\text { O menor grau de } \\
\text { detalhamento das } \\
\text { curvas de nível } \\
\text { e densidade de } \\
\text { drenagem reduz } \\
\text { os valores da } \\
\text { ponderação quanto } \\
\text { à estabilidade das } \\
\text { variáveis a elas } \\
\text { associadas. Essa } \\
\text { diferença reflete } \\
\text { no valor da média } \\
\text { calculada para } \\
\text { a determinação } \\
\text { do grau de } \\
\text { vulnerabilidade à } \\
\text { perda do solo, de } \\
\text { modo a torná-las } \\
\text { mais baixas. }\end{array}$ \\
\hline
\end{tabular}

Fonte: Fagundes (2013)

O Quadro 3 sintetiza a proposta de equivalência de classes entre as metodologias. Essa equiparação teve como princípio a associação dos respectivos níveis hierárquicos de classificação. 
Quadro 3 - Equivalência de classes

\begin{tabular}{|c|c|c|c|c|}
\hline $\begin{array}{l}\text { Classes de } \\
\text { fragilidade } \\
\text { ambiental }\end{array}$ & Grau de Fragilidade & $\begin{array}{c}\text { Classes de } \\
\text { vulnerabilidade a } \\
\text { erosão }\end{array}$ & $\begin{array}{c}\text { Valor médio } \\
\text { do grau de } \\
\text { vulnerabilidade }\end{array}$ & $\begin{array}{l}\text { Relação Pedogênese/ } \\
\text { Morfogênese }\end{array}$ \\
\hline Muito fraca & $1111\left(^{*}\right)$ & Estável & $1-1,3$ & Prevalece a Pedogênese \\
\hline Fraca & $\begin{array}{c}\text { Valores intermediários } \\
\text { específicos em cada } \\
\text { área }\end{array}$ & $\begin{array}{c}\text { Moderadamente } \\
\text { estável }\end{array}$ & $1,4-1,6$ & $\begin{array}{c}\text { Prevalece a Pedogênese } \\
\text { com aumento da } \\
\text { Morfogênese }\end{array}$ \\
\hline Média & $\begin{array}{c}\text { Valores intermediários } \\
\text { específicos em cada } \\
\text { área }\end{array}$ & $\begin{array}{l}\text { Medianamente } \\
\text { estável }\end{array}$ & $1,7-2,0$ & $\begin{array}{c}\text { Equilíbrio Pedogênese/ } \\
\text { Morfogênese }\end{array}$ \\
\hline Forte & $\begin{array}{c}\text { Valores intermediários } \\
\text { específicos em cada } \\
\text { área }\end{array}$ & $\begin{array}{l}\text { Moderadamente } \\
\text { vulnerável }\end{array}$ & $2,1-2,4$ & $\begin{array}{c}\text { Prevalece a } \\
\text { Morfogênese com } \\
\text { redução da Pedogênese }\end{array}$ \\
\hline Muito forte & $5555(* *)$ & Vulnerável & $2,5-3$ & $\begin{array}{l}\text { Prevalece a } \\
\text { Morfogênese }\end{array}$ \\
\hline
\end{tabular}

Fonte: Fagundes (2013).

$\left({ }^{*}\right)$ Representa o menor valor da variável.

$\left({ }^{* *}\right)$ Representa o maior valor da variável.

A elaboração das cartas de fragilidade ambiental e vulnerabilidade natural à perda solo, as combinações dos temas, o tratamento de imagens e a associação entre os bancos de dados foram executados no SIG ArcGis. Seus resultados podem ser observados nas Figuras 2 e 3 (Cf. Fagundes, 2013).

Na perspectiva metodológica, a proposta deste estudo de caso foi comparar o efeito da variação da escala nas duas metodologias. Buscou-se mensurar seu impacto na compartimentação da área de estudo, que é realizada, principalmente, pela matriz de dissecação do relevo (Ross, 1994) e pela interpretação das imagens de satélite (Crepani et al., 2001). Os trabalhos de campo e as consultas aos especialistas visaram a reduzir, na medida do possível, a subjetividade da hierarquização e da atribuição dos pesos às variáveis durante o processamento das metodologias. 

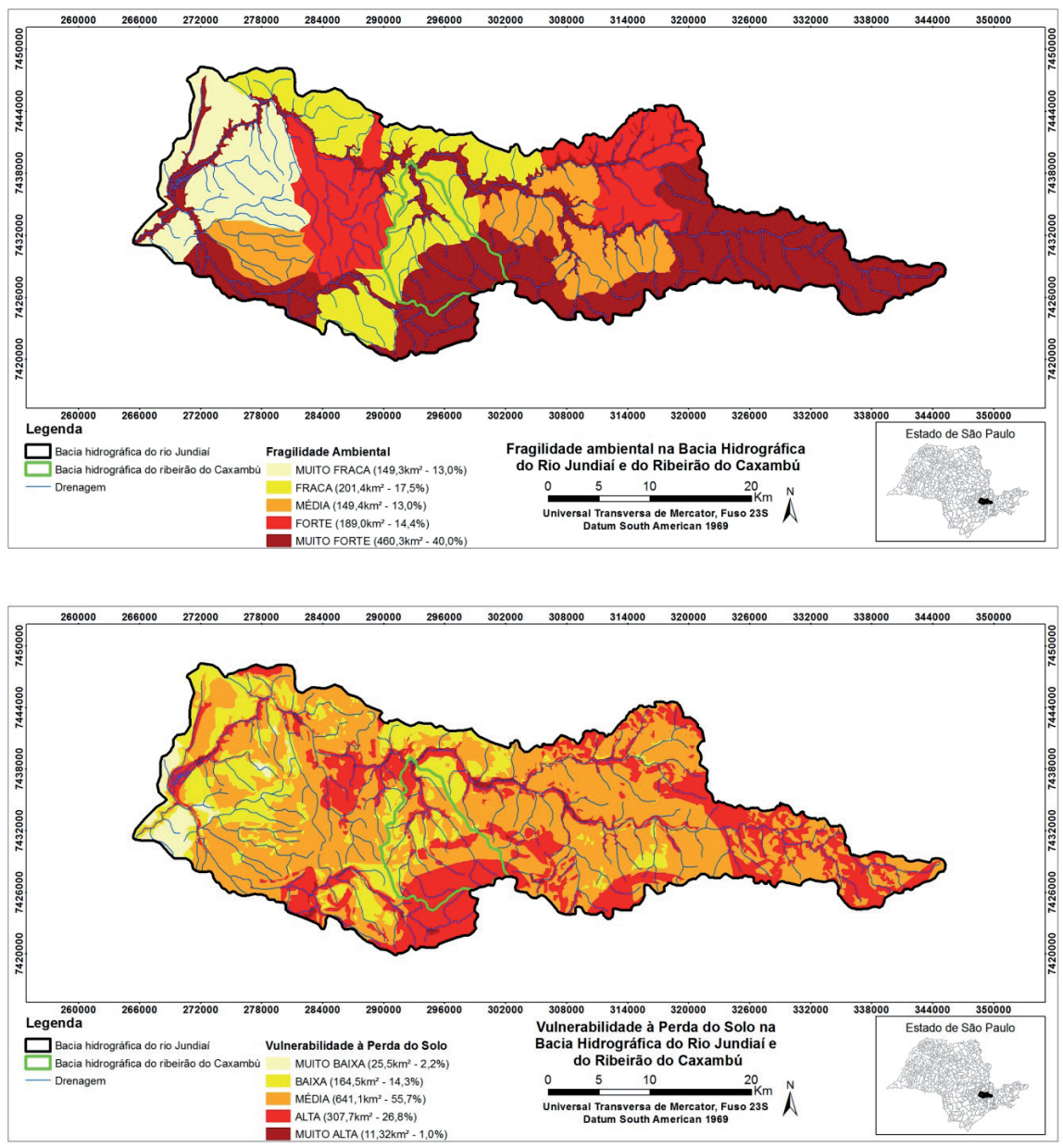

Figura 2 - Cartas de fragilidade e de vulnerabilidade, obtidas a partir das combinações temáticas na escala 1:50.000

Fonte: Fagundes (2013). 

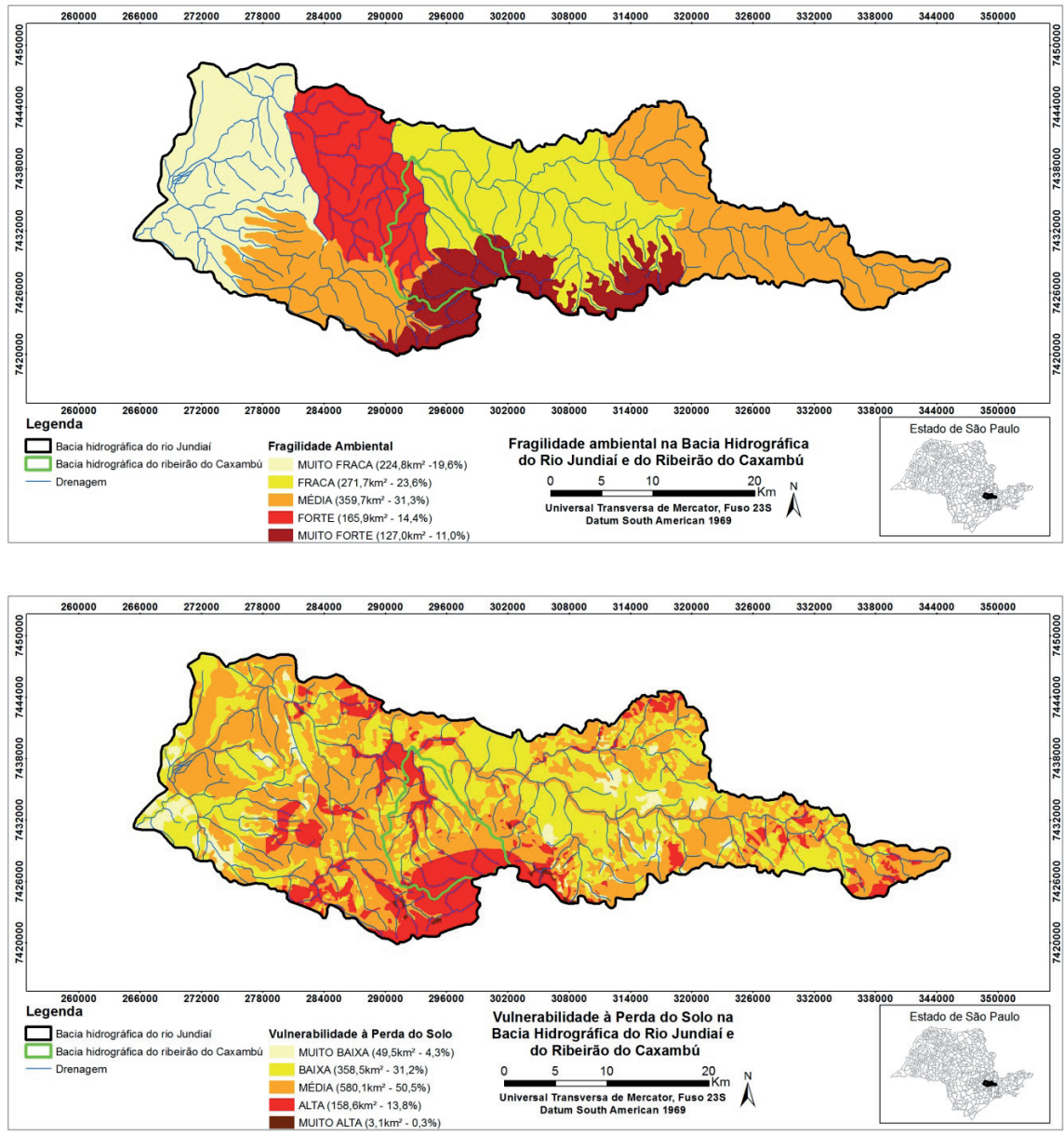

Figura 3 - Cartas de fragilidade e de vulnerabilidade, obtidas a partir das combinações temáticas na escala 1:250.000

Fonte: Fagundes (2013). 


\section{Resultados}

a) Fragilidade ambiental

No modelo de fragilidade ambiental, o tema geomorfologia mostrou-se mais sensível à variação de escala. A pedologia, o clima e o uso do solo não sofreram alteração significativa, pois ficam subjugados ao índice de dissecação do relevo. É essa variável que determina o grau de fragilidade de cada área, que ocorre em função do primeiro dígito (relevo). As demais variáveis definem a hierarquização por meio de seus coeficientes de fragilidade. A Tabela 1 e a Figura 4 mostram as áreas $\left(\mathrm{km}^{2}\right)$ de cada classe, nas escalas 1:50.000 e 1:250.000, obtidos pela metodologia de Ross.

Tabela 1 - Área das classes da metodologia de Ross (1994)

\begin{tabular}{|c|c|c|c|c|}
\hline CLASSE & $\begin{array}{c}\text { ÁREA KM } \\
\mathbf{1 : 5 0 . 0 0 0}\end{array}$ & $\begin{array}{c}\mathbf{\%} \\
\mathbf{1 : 5 0 . 0 0 0}\end{array}$ & $\begin{array}{c}\text { ÁREA KM } \\
\mathbf{1 : 2 5 0 . 0 0 0}\end{array}$ & $\begin{array}{c}\mathbf{\%} \\
\mathbf{1 : 2 5 0 . 0 0 0}\end{array}$ \\
\hline MUITO FRACA & 149,31 & 12,99 & 224,7682 & 19,56 \\
\hline FRACA & 201,43 & 17,52 & 271,7099 & 23,65 \\
\hline MÉDIA & 149,38 & 13,00 & 359,659 & 31,30 \\
\hline FORTE & 188,98 & 16,44 & 165,9463 & 14,44 \\
\hline MUITO FORTE & 460,33 & 40,05 & 126,9682 & 11,05 \\
\hline
\end{tabular}

Fonte: Ross (1994 apud Fagundes, 2013).

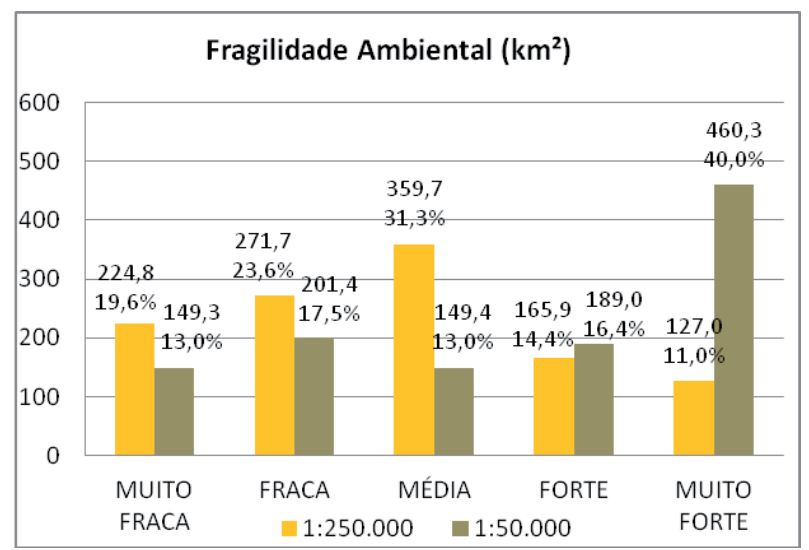

Figura 4 - Área das classes da metodologia de Ross (1994) Fonte: Ross (1994) apude Fagundes, 2013). 
A classe de fragilidade muito forte mostrou maior ocorrência na escala 1:50.000 ( $40 \%$ ou 460,3 km²). Acredita-se que essa situação tenha ocorrido em função do grau de detalhamento da carta topográfica, que permitiu a identificação de formas de relevo mais dissecadas. As demais classes não apresentaram variação significativa entre si, permanecendo em torno de 13 a $17 \%$.

Na escala 1:250.000, a classe de fragilidade média foi a que apresentou maior incidência $\left(31,3 \%\right.$ e $\left.359,7 \mathrm{~km}^{2}\right)$, seguida das classes fraca e muito fraca $\left(23,6 \%\right.$ e $271,7 \mathrm{~km}^{2}$; e $19,6 \%$, e $224,8 \mathrm{~km}^{2}$, respectivamente) e das classes forte e muito forte $\left(14,4 \%\right.$ e $165,9 \mathrm{~km}^{2}$; e $11 \%$ e $127 \mathrm{~km}^{2}$, respectivamente).

As regiões correspondentes à Serra do Japi (porção sul/sudoeste do município de Jundiaí) e a jusante da bacia hidrográfica do Rio Jundiaí (região de Indaiatuba e Salto) não apresentaram alteração do grau de fragilidade em função da variação da escala, embora possuam distintas características.

Na direção jusante predominam áreas com baixa densidade de drenagem e relevo pouco dissecado. A região da Serra do Japi caracteriza-se por áreas com alta densidade de drenagem e relevo bastante dissecado. Em ambos os exemplos, as formas de relevo não apresentaram elevada disparidade de identificação, quando sujeitas à variação de escala (1:50.000 para 1:250.000).

Esse quadro não se repetiu na região de montante da bacia hidrográfica do Rio Jundiaí (região de Mairiporã, Atibaia, Francisco Morato, Várzea Paulista, Campo Limpo Paulista). Mesmo apresentando características topográficas semelhantes, as curvas de nível e a densidade de drenagem não expressam a mesma concentração nas diferentes escalas.

A região a montante da bacia hidrográfica do Rio Jundiaí apresentou maior suscetibilidade à variação de escala nas cartas de fragilidade. $\mathrm{Na}$ escala 1:50.000, a região indicou fragilidade muito forte e forte, enquanto na escala 1:250.000, apresentou fragilidade média. Essa variação pode ser explicada pela redução do grau de detalhamento. A menor densidade de drenagem e os interflúvios maiores tornaram as formas de relevo suavizadas. A fragilidade ambiental foi atenuada, pois o agrupamento dos graus de fragilidade se dá em função do relevo (variável principal).

As planícies fluviais também se mostraram mais suscetíveis à variação de escala. Na escala 1:50.000, essas áreas indicaram fragilidade 
muito forte, por causa de sua sujeição a inundações periódicas. Na escala 1:250.000, entretanto, essa forma de relevo não foi representada, dada a generalização ocorrida no ajuste do tema geomorfologia (curvas de nível e padrão de drenagem na escala 1:250.000).

b) Vulnerabilidade à perda de solo

No modelo de vulnerabilidade, observou-se, comparativamente, menor sensibilidade à variação de escala. A Tabela 2 e a Figura 5 mostram as áreas $\left(\mathrm{km}^{2}\right)$ de cada classe, nas escalas 1:50.000 e 1:250.000, obtidas pela metodologia de Crepani et al. (2001).

Tabela 2 - Área das classes da metodologia de Crepani et al. (2001)

\begin{tabular}{|c|c|c|c|c|}
\hline CLASSE & $\begin{array}{c}\text { ÁREA KM } \\
\mathbf{1 : 5 0 . 0 0 0}\end{array}$ & $\begin{array}{c}\mathbf{\%} \\
\mathbf{1 : 5 0 . 0 0 0}\end{array}$ & $\begin{array}{c}\text { ÁREA KM } \\
\mathbf{1 : 2 5 0 . 0 0 0}\end{array}$ & $\begin{array}{c}\mathbf{1} \\
\mathbf{1 : 2 5 0 . 0 0 0}\end{array}$ \\
\hline MUITO BAIXA & 25,54 & 2,2 & 49,48 & 4,3 \\
\hline BAIXA & 164,55 & 14,3 & 358,46 & 31,18 \\
\hline MÉDIA & 641,10 & 55,7 & 580,13 & 50,46 \\
\hline ALTA & 307,76 & 26,8 & 158,62 & 13,8 \\
\hline MUITO ALTA & 11,32 & 1,0 & 3,07 & 0,27 \\
\hline
\end{tabular}

Fonte: Crepani et al. (2001, apud Fagundes, 2013)

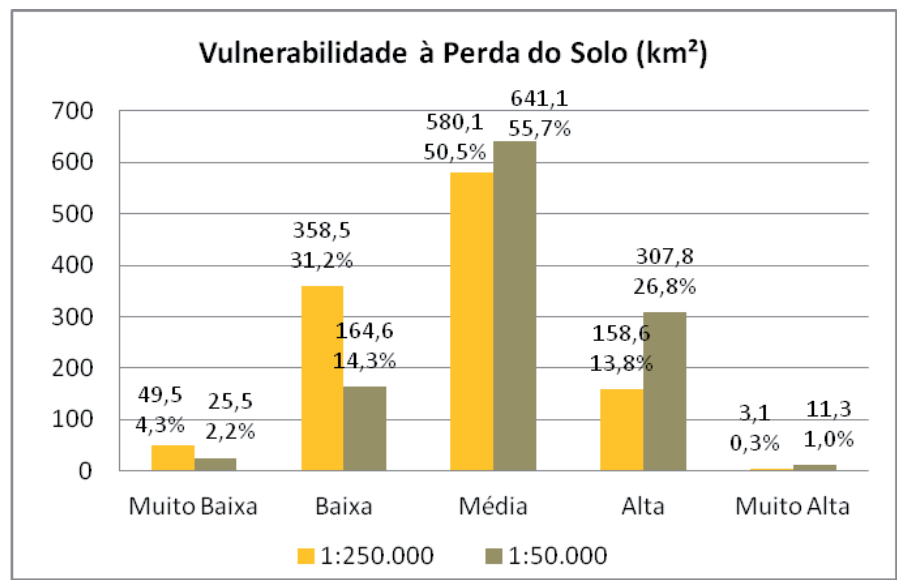

Figura 5 - Área das classes da metodologia de Crepani et al. (2001) Fonte: Crepani et al. (2001 apud Fagundes, 2013) 
$\mathrm{Na}$ escala 1:50.000, a classe de vulnerabilidade que apresentou maior grau de incidência foi a média $\left(55,7 \%\right.$ e $\left.641,1 \mathrm{~km}^{2}\right)$, seguida da alta $\left(26,8 \%\right.$ e $\left.307,8 \mathrm{~km}^{2}\right)$, baixa $\left(14,3 \%\right.$ e $\left.164,6 \mathrm{~km}^{2}\right)$, muito baixa $(2,5 \%$ e 25,5 $\left.\mathrm{km}^{2}\right)$ e muito alta $\left(1 \%\right.$ e $\left.11,3 \mathrm{~km}^{2}\right)$.

Na escala 1:250.000, a classe que mais ocorreu também foi a média $\left(50,5 \%\right.$ e $\left.580,1 \mathrm{~km}^{2}\right)$, seguida da baixa $\left(31,2 \%\right.$ e $\left.358,5 \mathrm{~km}^{2}\right)$, alta $(13,8 \%$ e $\left.158,6 \mathrm{~km}^{2}\right)$, muito baixa (4,3\% e 49,5 $\left.\mathrm{km}^{2}\right)$ e muito alta $\left(0,3 \%\right.$ e $\left.3,1 \mathrm{~km}^{2}\right)$.

Percebe-se que, independentemente da escala, as duas cartas de vulnerabilidade apresentaram os valores extremos atenuados e valores medianos preponderantes. Acredita-se, consequentemente, que a forma de cálculo dessa metodologia, baseada nas médias dos temas, se mostrou mais importante do que o nível de detalhamento das representações cartográficas.

A região central, bem como a montante da bacia hidrográfica do Rio Jundiaí, apresentou resultados consideravelmente distintos em relação à variação de escala. Na 1:50.000, as classes predominantes foram média e forte, enquanto na 1:250.000, foram média e baixa. Acredita-se que os principais responsáveis por esta diferença sejam as formas de relevo e os solos, visto que esses temas foram adaptados com base nas cartas topográficas 1:50.000 e 1:250.000.

A região da Serra do Japi e a jusante da bacia hidrográfica do Rio Jundiaí apresentaram resultados consideravelmente semelhantes em relação à variação de escala, com predominância da classe forte na primeira, e média e baixa na segunda. Em ambas as escalas, os temas também não apresentaram variação representativa na região da Serra do Japi. Nela, há o predomínio da cobertura vegetal, sustentada por um relevo rugoso com solos rasos. O mesmo ocorreu na porção a jusante da bacia, cujo relevo é mais suave; as declividades, baixas; o padrão de drenagem, menos denso; e os solos, mais profundos.

\section{Discussão}

Como era previsto, as metodologias geraram mapas diferentes, com baixa correlação entre si. Essas diferenças foram maximizadas com a ampliação da escala e minimizadas com a sua redução, mas de forma não linear, como ilustram as Figuras 6 e 7. 


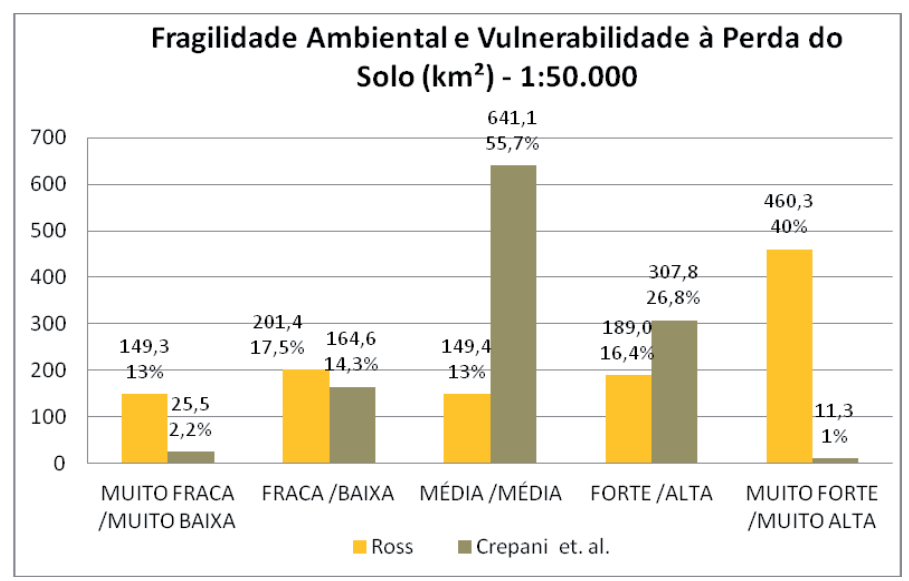

Figura 6 - Comparação entre as áreas das classes $\left(\mathrm{km}^{2}\right)$ na escala 1:50.000

Fonte: Fagundes (2013)

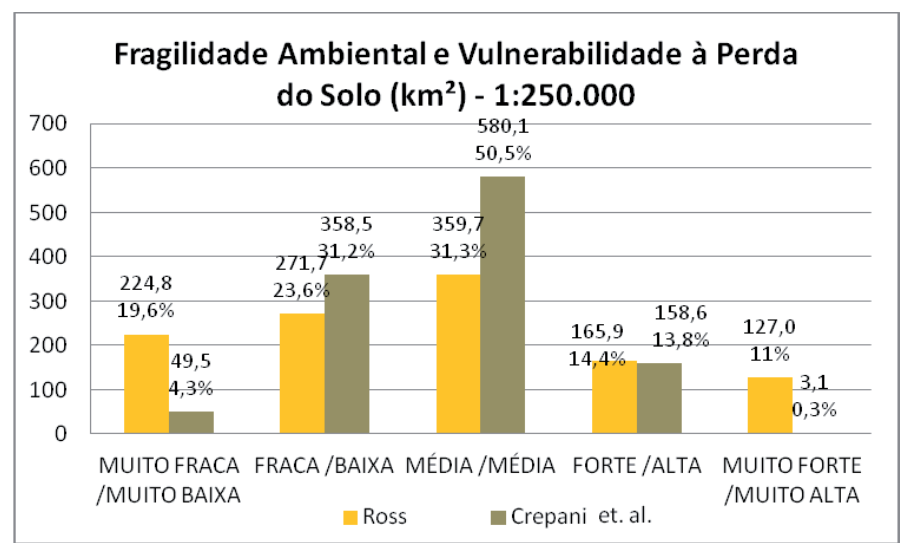

Figura 7 - Comparação entre as áreas das classes $\left(\mathrm{km}^{2}\right)$ na escala 1:250.000 Fonte: Fagundes (2013).

Na escala 1:50.000, as classes que apresentaram maior divergência foram a média, com 55,7\% (641,1 km²) em Crepani et al. (2001) e 13\% (149,4 $\mathrm{km}^{2}$ ) em Ross (1994), e muito forte/muito alta, com 1\% (11,3 km²) com base nos primeiros autores, e 40\% (460,3 $\left.\mathrm{km}^{2}\right)$, no segundo.

Na escala 1:250.000, os resultados também foram divergentes, ainda que em menor proporção. A classe que apresentou maior discrepância 
também foi a média, com 50,5\% (580,0 $\left.\mathrm{km}^{2}\right)$ em Crepani et al. (2001) e $31,3 \%$ (359,7 $\left.\mathrm{km}^{2}\right)$ em Ross (1994), seguida da muito fraca / muito baixa, com 4,3\% (49,5 $\left.\mathrm{km}^{2}\right)$, com base nos primeiros autores, e 19,6\% $(224,8$ $\mathrm{km}^{2}$ ), no segundo.

De modo geral, nota-se que as classes das duas metodologias na escala 1:50.000 foram mais divergentes entre si, quando comparadas às classes na escala 1:250.000. Acredita-se que isso ocorra devido ao nível de detalhamento mais elevado das bases utilizadas para a confecção dos mapas na escala maior.

No que se refere à localização espacial, nota-se que o efeito da variação de escala nas metodologias ocasionou divergências à montante e na porção central da bacia hidrográfica do Rio Jundiaí. As principais semelhanças ocorreram na Serra do Japi e à jusante da bacia (Tabela 3 e Figura 8).

Tabela 3 - Semelhanças e diferenças das áreas das classes (de acordo com a localização)

\begin{tabular}{|c|c|c|c|c|}
\hline \multirow{2}{*}{ Situação } & \multicolumn{2}{|c|}{$\mathbf{1 : 2 5 0 . 0 0 0}$} & \multicolumn{2}{c|}{$\mathbf{1 : 5 0 . 0 0 0}$} \\
\cline { 2 - 5 } & Área $\mathbf{k m}^{\mathbf{2}}$ & $\mathbf{\%}$ & Área $\mathbf{k m}^{\mathbf{2}}$ & \% \\
\hline Diferença & 729,0 & 63,4 & 967,4 & 84,1 \\
\hline Semelhança & 421,2 & 36,6 & 183,3 & 15,9 \\
\hline
\end{tabular}

Fonte: Elaborada pelos autores.

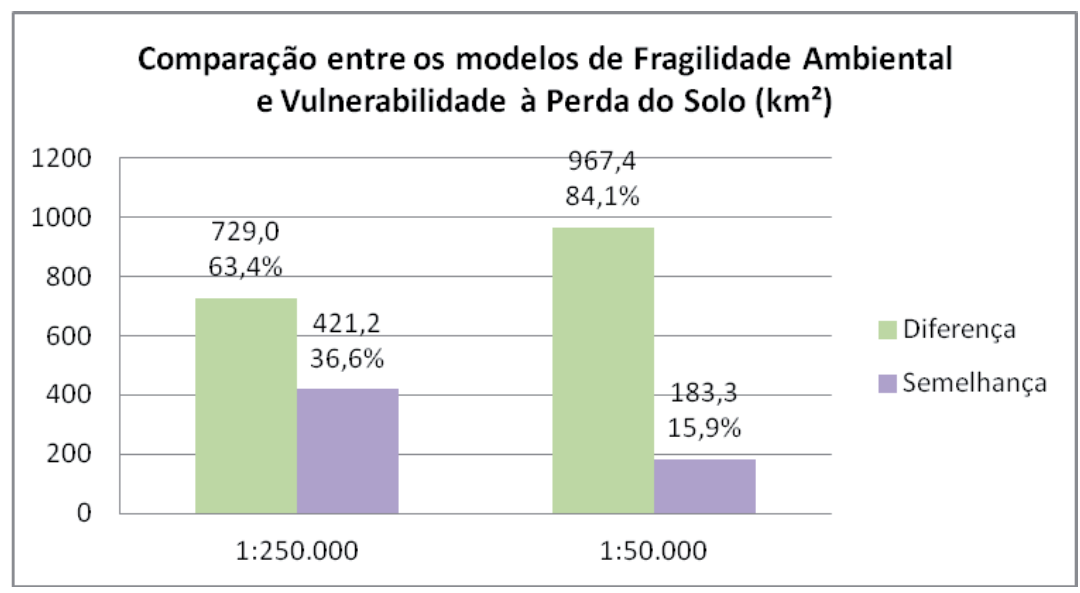

Figura 8 - Distribuição das classes entre os modelos de fragilidade e vulnerabilidade, de acordo com a localização

Fonte: Elaborada pelos autores. 
Neste caso, a escala 1:250.000 apresentou um percentual maior de semelhança $\left(36,6 \%\right.$ e $\left.421,0 \mathrm{~km}^{2}\right)$ entre as metodologias, quando comparada à escala 1:50.000 $\left(15,9 \%\right.$ e 183,3 $\left.\mathrm{km}^{2}\right)$. De modo geral, independentemente da escala, as duas metodologias divergiram bastante entre si. $\mathrm{Na}$ escala 1:50.000, essa diferença alcançou $84,1 \%\left(967,4 \mathrm{~km}^{2}\right)$, enquanto na escala 1:250.000, a porcentagem foi de $63,4 \%\left(729,0 \mathrm{~km}^{2}\right)$.

Essa diferença parece ser decorrente da generalização dos dados na escala 1:250.000, que possui equidistância maior entre curvas de nível, menor densidade de drenagem e de interflúvios. Esses fatores amenizaram a declividade, ao mesmo tempo que possibilitaram a interpretação de formas de relevo mais suavizadas e solos mais desenvolvidos.

O detalhamento da classificação das áreas mostrou-se diretamente proporcional à escala das bases disponíveis. Observou-se que quanto maior a escala das variáveis utilizadas, maior a diferença entre os mapas de fragilidade ambiental e vulnerabilidade à perda do solo. A recíproca também é verdadeira: quanto menor a escala, maior a semelhança entre os produtos.

\section{Considerações finais}

Neste estudo de caso sobre o efeito da variação de escala nas metodologias desenvolvidas por Ross (1994) e por Crepani et al. (2001), constatou-se que:

- a metodologia de fragilidade é mais sensível à mudança de escala, em função do grau de detalhamento das representações cartográficas;

- a metodologia de vulnerabilidade mostrou-se mais influenciada pela forma de cálculo das classes do que pela variação de escala.

Diante dos resultados, considera-se que a escala não pode ser utilizada como elemento principal no processo de escolha entre as metodologias. Mas acredita-se ser muito importante contextualizar as suas variações, pois elas se ampliaram em função do aumento da escala, mas de forma não linear.

$\mathrm{Na}$ metodologia de fragilidade, a escala cartográfica 1:250.000 apresentou menor densidade de drenagem e maiores interflúvios com de- 
clividade e formas de relevo mais suavizadas. Com as formas de relevo suavizadas, a fragilidade ambiental foi atenuada. Deste modo, as classes forte e muito forte foram mais expressivas na escala 1:50.000, enquanto as classes fraca e muito fraca apareceram com maior frequência na escala 1:250.000.

Na metodologia de Crepani et al. (2001), as classes extremas (muito baixa e muito forte) foram suavizadas devido à média aritmética da ponderação dos temas. Independentemente da escala, as duas cartas de vulnerabilidade à perda do solo apresentaram valor mediano preponderante e valores extremos atenuados.

Constatou-se que a metodologia de Crepani et al. (2001) atenuou os valores extremos e acentuou os valores intermediários, enquanto a de Ross (1994) atenuou os valores intermediários e acentuou os extremos. Assim, quanto maior for a escala dos mapas temáticos, maior deverá ser a diferença entre os mapas de fragilidade ambiental e vulnerabilidade à perda do solo. E, quanto menor for a escala dos mapas, maior deverá ser a semelhança entre as metodologias.

Esse resultado reforça a perspectiva de Racine et al. (1983), de que a tendência à homogeneidade cresce na razão inversa da escala. Em outras palavras, os autores destacam a tendência à heterogeneidade do conteúdo nas escalas maiores, e à homogeneidade, nas escalas menores.

\section{Referências}

ASPINALL, R.; PEARSON, D. Integrated geographical assessment of environmental condition in water catchments: linking landscape ecology, environmental modelling and GIS. Journal of Environmental Management, v. 59, p. 299-319, 2000.

AVISON, D.; FITZGERALD, G. Information Systems Development Methodologies, Techniques \& Tools. London: McGraw-Hill McGraw Hill. 1995.

CREPANI, E.; MEDEIROS, J. S.; FILHO, P. H.; FLORENZANO, T. G.; DUARTE, V.; BARBOSA, C. C. F. Sensoriamento remoto e Geoprocessamento aplicados ao zoneamento Ecológico-Econômico e ao Ordenamento Territorial. Instituto Nacional de Pesquisas Espaciais (INPE), São José dos Campos, SP, 2001.

FABRIKANT, S. I. Evaluating the usability of the scale metaphor for querying semantic information spaces. In: Spatial Information Theory: foundations of Geographic Information Science. Conference on Spatial Information Theory (COSIT '01). Lecture Notes in Computer Science 2205. Montello, D. R. (Ed.). Berlin: Springer Verlag, 2001. p. 156-171. Disponível em: <http://www.geog.ucsb. 
edu/ sara/html/research/ cosit01/fabrikant_cosit01.pdf $>$. Acesso em: 14 jul. 2013.

FAGUNDES, M. G. Estudo comparativo da variação de escala na fragilidade ambiental e vulnerabilidade natural do solo na bacia hidrográfica do rio Jundiaí. Dissertação (Mestrado em Geografia). Departamento de Geografia da Faculdade de Filosofia Letras e Ciências Humanas da Universidade de São Paulo. São Paulo, 2013.

GENELETTI, D. A GIS-based decision support system to identify nature conservation priorities in an alpine valley. Land Use Policy, v. 21, p. 149-160, 2004.

GOODCHILD, M. F.; QUATTROCHI, D. A. Scale, multiscaling, remote sensing and GIS. In: QUATTROCHI, D. A.; GOODCHILD, M. F. Scale in remote sensing and GIS. Boca Raton: Lewis Publishers. 1997. p. 1-11.

SÃO PAULO (Estado). Instituto de Pesquisas Tecnológicas (IPT). Mapa Geomorfológico do Estado de São Paulo. São Paulo: IPT, 1981.

LECHNER, A. M.; LANGFORD, W. T.; JONES, S. D.; BEKESSY, S. A.; GORDON, A. Investigating species-environment relationships at multiple scales: Differentiating between intrinsic scale and the modifiable areal unit problem. Ecological Complexity, v. 11, p. 91-102, 2012.

MARCEAU, D. J.; HAY, G. J. Remote sensing contributions to the scale issue. Canadian Journal of Remote Sensing, v. 25, p. 357-366, 1999.

McKINNEY, D. C.; CAI, X. M. Linking GIS and water resources management models: an object-oriented method. Environmental Modelling \& Software, Netherlands, v. 7, p. 413-425, 2002.

MELO, O. A. G.; SANTOS, M. L. Análise comparativa da vulnerabilidade ambiental potencial ou emergente da bacia hidrográfica do rio Baiano - Assis Chateaubriand/PR. Boletim de Geografia de Maringá, Maringá, SP, v. 28, n. 2, p. 17-27, 2010.

OPENSHAW, S. A geographical solution to scale and aggregation problems in region-building, partitioning and spatial modelling. Institute of British Geographers, Transactions, New Series 2, p. 459-472, 1977.

QUEIROZ FILHO, A. P.; RODRIGUES, M. Arte de voar em mundos virtuais. São Paulo: Annablume, 2007.

RACINE, J. B.; RAFFESTIN, C.; RUFFY, V. Escala e ação, contribuições para uma interpretação do mecanismo de escala na prática da Geografia. Revista Brasileira de Geografia, Rio de Janeiro, v. 45, n. 1, p. 123-135, 1983.

RAGIN, C. C. The comparative method: moving beyond qualitative and quantitative strategies. Los Angeles: University of California Press, 1987.

ROSS, J. L. S. O Registro cartográfico dos fatos geomórficos e a questão da taxonomia do relevo. Revista do Departamento de Geografia, USP, São Paulo. n. 6, p. 17-29, 1992.

. Análise empírica da fragilidade dos ambientes naturais antropizados. Revista do Departamento de Geografia, São Paulo, n. 8, p. 51-62, 1994. 
; MOROZ, I. C. Mapa geomorfológico do Estado de São Paulo. Revista do Departamento de Geografia, v. 11, p. 57-66, 1997.

SANTOS, C. A.; SOBREIRA, F. G. Análise da fragilidade e vulnerabilidade natural dos terrenos aos processos erosivos como base para o ordenamento territorial: o caso das bacias do córrego Carioca, córrego do Bação e ribeirão Carioca na região do alto rio das Velhas-MG. Revista Brasileira de Geomorfologia, Porto Alegre, v. 9, n. 1, p. 65-73, 2008.

SOTCHAVA, V. B. Por uma teoria de classificação de geossistemas de vida terrestre. São Paulo. Revista IG-USP, São Paulo, Cadernos de Biogeografia, n. 14, 1978.

SPORL, C. Análise da fragilidade ambiental relevo-solo com aplicação de três modelos alternativos nas altas bacias do Rio Jaguari-Mirim, Ribeirão do Quartel e Ribeirão da Prata. Dissertação (Mestrado em Geografia). Departamento de Geografia da Faculdade de Filosofia Letras e Ciências Humanas da Universidade de São Paulo. São Paulo, 2001.

SPORL, C.; CASTRO, E. G.; LUCHIARI, A. Aplicação de Redes Neurais Artificiais na Construção de Modelos de Fragilidade Ambiental. Revista do Departamento de Geografia, USP, São Paulo, v. 21, p. 113-135, 2011.

TRICART, J. Ecodinâmica. Rio de Janeiro: IBGE/Supren, 1977.

TURNER, M. G. Landscape ecology: the effect of pattern on process. Annual Review of Ecology and Systematics, v. 20, p. 171-197, 1989.

VALAVANIS, V. D.; GEORGAKARAKOS, S.; KAPANTAGAKIS, A.; PALIALEXIS, A.; KATARA, I. A GIS environmental modelling approach to essential fish habitat designation. Ecological modeling, Netherlands, v. 178, p. 417-427, 2004.

YING, X.; GUANG-MINGA, Z.; GUI-QIUA, C.; LINA, T.; KE-LINC, W.; DAO-YOUC, H. Combining AHP with GIS in synthetic evaluation of eco-environment quality, a case study of Hunan Province, China. Ecological modeling, Netherlands, v. 209, p. 97-109, 2007.

Mariana Guarnier Fagundes - Possui graduação em Geografia pela Pontifícia Universidade Católica de São Paulo e mestrado em Geografia pela Universidade de São Paulo.

Alfredo Pereira de Queiroz Filho - Possui graduação em Geografia pela Universidade de São Paulo. Mestrado em Engenharia pela Escola Politécnica da Universidade de São Paulo e Doutorado pela mesma instituição. Possui Pós-doutorado pelo Institut des Hautes Etudes de l'Amérique Latine (IHEAL) Université Paris III Sorbonne Nouvelle. Atualmente é professor da Universidade de São Paulo. 